\title{
Effect on hyperglycemia and pancreas cells of chaya aqueous extracts from two different regions in streptozotocin-induced diabetes rats
}

\author{
Eduardo Lozano Guzmán ${ }^{\circledR *}$, José Cruz Calderón González', \\ Maribel Cervantes Flores ${ }^{1}$, Ada Sandoval Carrillo², \\ María Guadalupe Nieto Pescador ${ }^{1}$, Francisco Javier Moreno Cruz ${ }^{1}$ \\ ${ }^{1}$ Faculty of Chemical Sciences, Juarez University of the State of Durango, Durango, Dgo., Mexico, \\ ${ }^{2}$ Institute of Scientific Research, Universidad Juárez of the State of Durango, Durango, Dgo., Mexico
}

\begin{abstract}
Cnidoscolus chayamansa is a native plant of the Mayan region, which is also cultivated in other places like northern Mexico, Tunisia and India. Many properties are attributed to Mayan Chaya, such as aid in the control of glycemia in diabetics. Thus this study aimed to evaluate the hypoglycemic effects of chaya aqueous extracts in a model of streptozotisin-induced diabetic Wistar rats. Chaya aqueous extracts were collected from plants cultivated in Quinta Roo (Mayan region) and Durango (northern Mexico), and in this study we compare their effect with metformin (as a control). Additionally, we compared the extracts mass profiles from both regions by high-resolution liquid chromatography coupled to a triple quadrupole tandem mass detector (HPLC-MS/MS QQQ). Finally, a study of the pancreatic tissue was carried out to evaluate the effects of the extracts on the Langerhans islets. Both extracts showed a good hypoglycemic effect after two weeks of treatment, and the Langerhans islets showed a partial recovery due to the effect of the treatment. Although the plants were cultivated at a distance of $2,350 \mathrm{~km}$ and under different weather, the compounds found in both did not show significant differences.
\end{abstract}

Keywords: Diabetes. Chaya. Langerhans islets. Hypoglycemia. HPLC.

\section{INTRODUCTION}

The plant called chaya (Cnidoscolus chayamansa) has its origin in the southeast of Mexico, especially the Yucatan Peninsula and Guatemala. This plant is also cultivated in different regions with warm weather in Mexico, and in different countries such as Tunisia and India. In Yucatan and Quintana Roo it is cultivated in backyards and gardens, is used as an ornamental plant, and it is used to prepare many dishes too. The Mayans cultivated it for their nutritional, medicinal

*Correspondence: E. Lozano Guzmán, Pharmacognosy Laboratory, Faculty of Chemical Sciences, Juarez University of the State of Durango, Durango, Dgo., Mexico.E-mail: elozano@ujed.mx and culinary properties (Moya et al., 2017). It is known that chaya has a high content of iron, potassium and calcium, it also provides vitamin $\mathrm{A}, \mathrm{C}$ and $\mathrm{E}$ and contains high protein values (Kuti, Torres, 1996). It has been traditionally recommended for various conditions such as diabetes, obesity, kidney stones, hemorrhoids, acne, visual and gum problems. Chaya leaves have been taken as a laxative, diuretic, for circulation, to improve digestion, and to stimulate lactation (Valenzuela et al., 2015). Although its popularity continues to rise, there are not many scientific reports about it. The present work was focused to check and compare the hypoglycemic effects in streptozotocininduced diabetes mellitus type 2 rats of fresh leaves of Chaya grown up on Quintana Roo (Mayan region 
-CQR-) and Durango (north of México-CDGO). The results suggest that the extracts provide good glycemic control. Additionally, a partial regeneration of the islets of Langerhans was observed after treatment. The substances detected in both samples did not show differences.

\section{MATERIAL AND METHODS}

\section{Chaya and extracts}

Two types of fresh chaya leaves were used, one from the Mayan region of Quintana Roo (CQR $19^{\circ} 36^{\circ} \mathrm{N}-87$ $\circ 55^{\prime} \mathrm{W}$ ) and the other from Durango (CDGO $24^{\circ} 56$ ' $05^{\prime}$ ' $\mathrm{N}-104^{\circ}, 54$ ' $43^{\prime}$ ' 'W). The extracts were obtained by weighing $15 \mathrm{~g}$ of fresh leaf/L water and boiling for 5 min. These were delivered ad libitum and renewed daily. The daily consumed volume of both, water and extracts, was also measured.

\section{Induction to diabetes}

Induced diabetes was carried out by intraperitoneal injection of streptozotocin at a dose of $60 \mathrm{mg} / \mathrm{kg}$. Streptozoticin is commonly used as an antitumor, however, it is known to also cause damage in the islets of Langerhans, interfere with DNA methylation and inhibit the enzyme $N$-acetyl-bD-glucosimidase, making it a suitable drug to induce diabetes in laboratory animals (Becquer et al., 2016). Once the hyperglycemia was checked (48 hours later), the treatments were administered.

\section{Design}

Twenty-five Wistar rats were used, all females weighing $228 \pm 22 \mathrm{~g}$. They were kept at a temperature of $27 \pm 5{ }^{\circ} \mathrm{C}$ respecting the circadian cycles and were fed with commercial pellets (Rodent Chow Purina ${ }^{\circledR}$ ). Each rat was housed in an individual cage. The experiment was conducted fulfilling the norm NOM062-ZOO-199 that establishes the care and ethical aspects in the experimentation in laboratory animals. The fulfillment of the ethical aspects was certified by MVZ Gerardo del Campo G. The rodents were randomly divided into 5 groups: group A remained healthy and untreated (negative control). Groups B, C $\mathrm{D}$ and $\mathrm{E}$ were induced to diabetes. Group B did not receive any treatment (positive control). Group $\mathrm{C}$ was treated with metformin at a daily morning dose of 100 $\mathrm{mg} / \mathrm{kg}$. (Metformin was taken as a reference because its action includes pancreatic and extrapancreatic mechanisms, inhibits hepatic gluconeogenesis and increases glycolysis, - Chávez et al., 2001; Chavez et al., 2007). Group D was treated with CQR and group E was treated with CDGO. Weekly fasting glycemia was taken by Accu-check Sensor glucometer (Roche (B). An ANOVA was applied to compare intergroup differences and a post hoc analysis, which included Tukey and Bonferroni test were also applied. The statistical package SPSS v. 22 was used. At the end, the rats were desensitized by ether and then sacrificed. After this, the pancreas was extracted and was preserved in $10 \%$ formaldehyde. Then a LEICA DSC1 microtome was used to obtain cuts that were fixed on a glass slide and then stained according to the hematoxylin eosin technique (Pan Reac Química, 2017). The tissue was analyzed under a microscope.

\section{Mass spectrometry}

To identify the compounds present in the extracts, an Agilent chromatograph mod. 1200 coupled to a triple quadrupole tandem mass detector was used. ESI nebulizer chamber at a temperature of $200{ }^{\circ} \mathrm{C}$ was used to ionize. The mobile phase was formed by an aqueous solution of $0.1 \%$ Formic Acid and Acetonitrile in a proportion of $65 / 35 \% \mathrm{v} / \mathrm{v}$. The separation of the compounds was carried out on a Zorbax Eclipse XDB-C18 4.5x150 mm-5 um column. The extracts were diluted in mobile phase in a ratio of 1: 500 . Two $\mathrm{uL}$ of each extract were then injected to the chromatograph. The detector was used at a rate of 500 scans per second and the elution was left up to 15 minutes. The spectra were later analyzed. Injections of each solvent, including water, were also analyzed to discard the masses present in them. All solvents used had HPLC purity.

\section{RESULTS}

\section{Hypoglycemic effect}

During the adaptation period, all the groups of rats averaged a glycemia of $130 \pm 2 \mathrm{mM} / \mathrm{dL}$. However, 48 hours after the induction of diabetes, the groups with diabetes averaged levels of $398 \pm 36 \mathrm{mM} / \mathrm{dL}$. 
As shown in Figure 1, groups C, D and E lowered their blood sugar levels to normal ranges. After the first week of treatment, groups $\mathrm{C}, \mathrm{D}$ and $\mathrm{E}$ did not show significant differences $(\mathrm{p} \leq 0.05)$ with respect to group A (healthy rats). The Tukey and Bonferroni tests also showed no significant differences between the three treatments. In contrast, the diabetic group (B) remained with high blood sugar throughout the experiment (322 \pm $42 \mathrm{mM} / \mathrm{dL}$ ).

Regarding the histopathological study of pancreatic tissue, a partial recovery was observed in the islets of Langerhans. Figure 2 shows three stages of pancreatic tissues: panel A shows the cut of a healthy rat before being subjected to diabetes induction. Panel B shows the islets of Langerhans diminished due to the action of streptozotocin during the induction of diabetes. Panel $\mathrm{C}$ shows the state of the pancreatic tissue at the end of the treatment, in this case with CDGO. This partial recovery was not seen in the rats that were treated only with metformin.

The analysis of the extracts by HPLC (Figure 3) suggests the presence of Rutin, Naringenin, Chlorogenic acid, Ferulic acid, Protocatechico acid, Astragalina, Caffeic acid, Myristic acid, Riboflavin, b-carotene, quercetin and palmitic acid. Rutin was the compound with the highest ionic abundance $(240,000)$, while ferulic acid presented an abundance of 3800 and Naringenin an ionic abundance of 1800 , as can be seen in figure 3. No significant differences were detected between the compounds present in $\mathrm{CDGO}$ and $\mathrm{CQR}$.

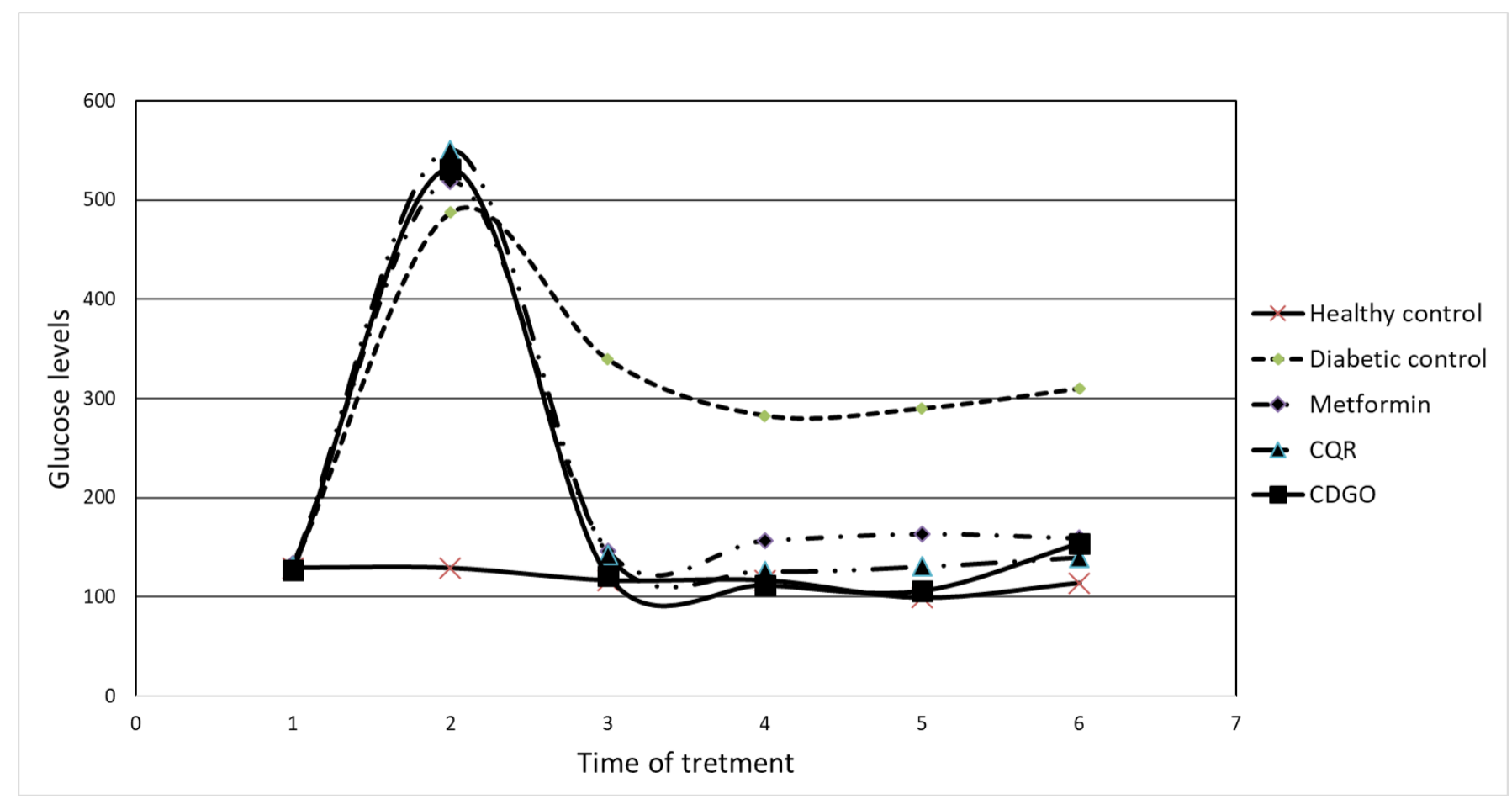

FIGURE 1 - Index of glycemia of the different treatments. 1) Induction to diebates, 2) Start of treatment 48 hours later, 3 ) Glycemia at one week of treatment, 4) Glycemia at 20 days of treatment, 5) Glycemia at 30 days of treatment, 6) Glycemia at 7 weeks of treatment. 

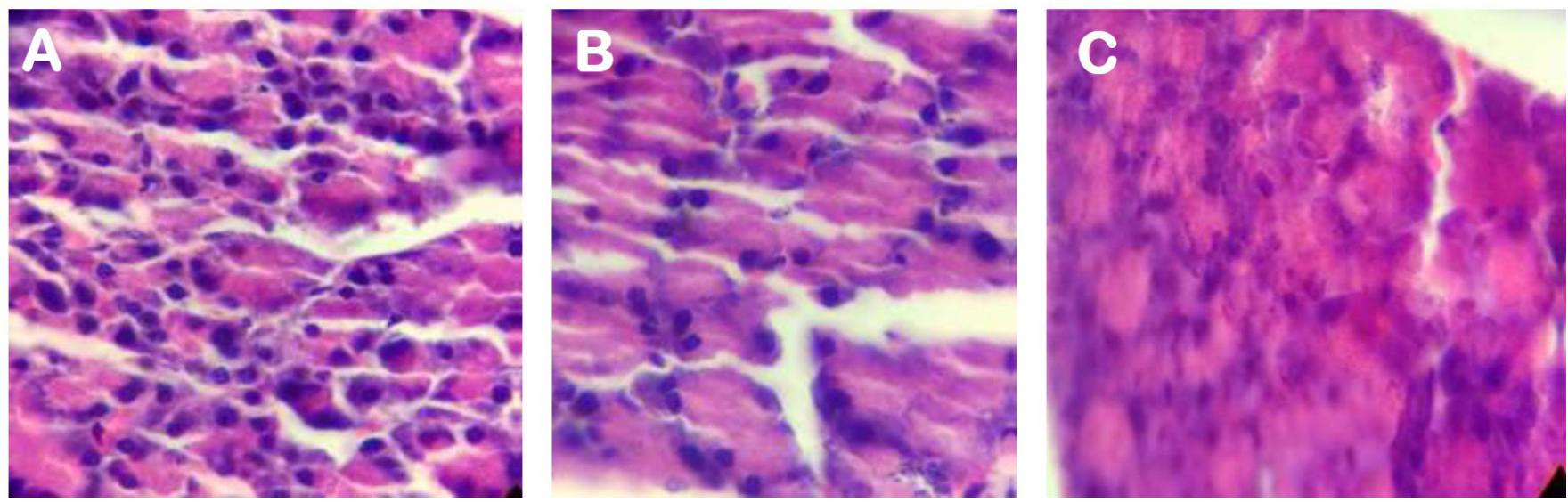

FIGURE 2 - Histopathological study of the pancreas, before and during the induction of diabetes (A and B) and at the end of the treatment with CDGO $(\mathrm{C})$.
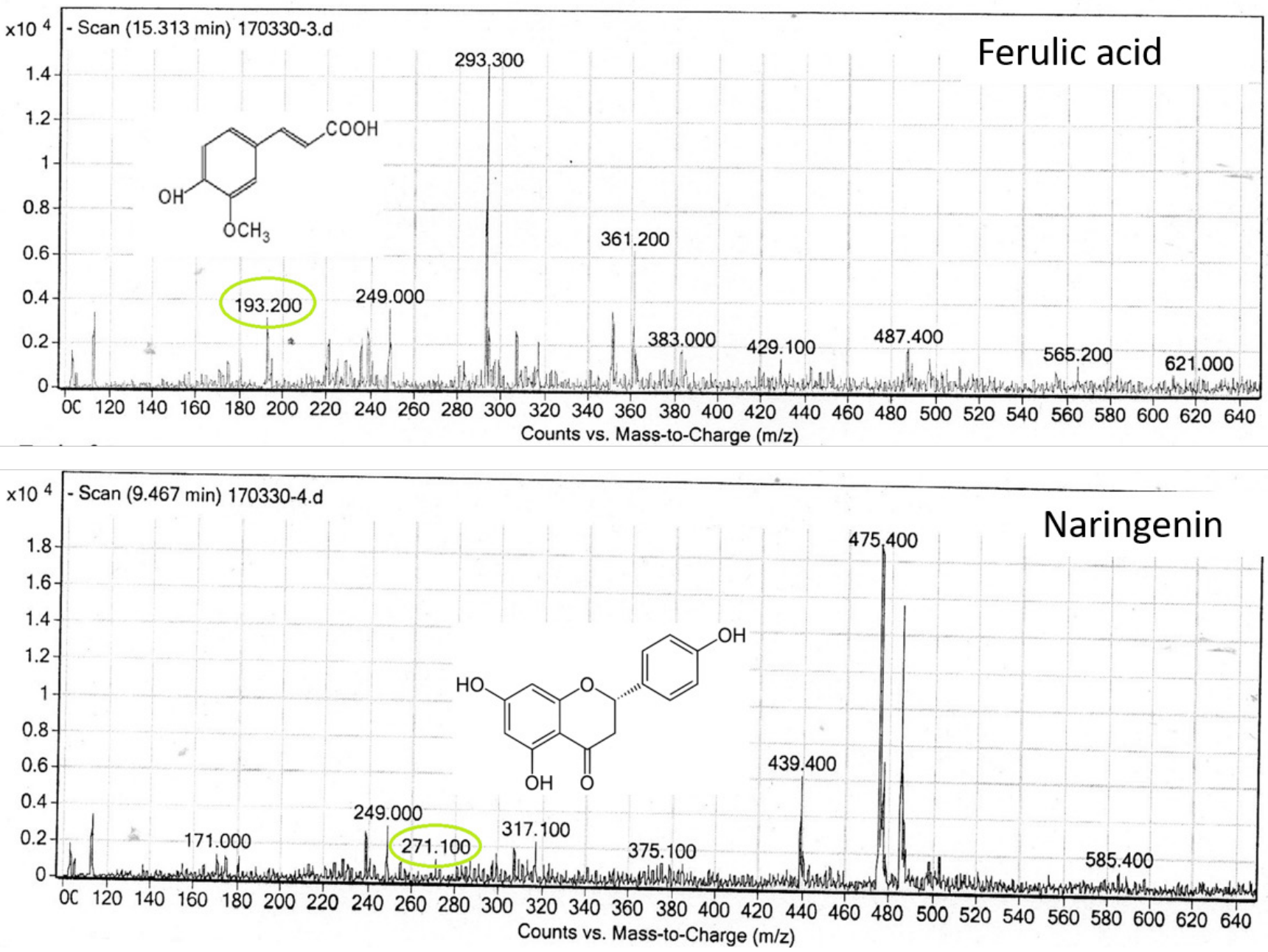

FIGURE 3 - Chromatograms showing some of the substances identified in the extracts based on their mass/charge ratio (m/z). 


\section{DISCUSSIONS}

Although the extracts of plants from two different regions were evaluated, they did not present significant differences in terms of the compounds present in them and in terms of their hypoglycaemic effect. Apparently the climate or the type of land in which the plant is cultivated has little influence on its beneficial effects. The hypoglycemic effects found in the murine model may be due mainly to the presence of Naringenin, Ferulic acid, Riboflavin and Quercetin of both extracts. Naringenin generally improves insulin sensitivity and helps to depress glucose tolerance (Shih-Jej et al., 2011; Orsolic et al., 2011). Ferulic acid is also a good adjunct to the control of diabetes. After treating diabetic rats with ferulic acid, the authors of this study found that the compound increased the antioxidant capacity of the animals and helped regulate their blood sugar levels, (Balasubashini et al., 2004). In addition, Manikandan et al. (2012) found that the combination of ferulic acid and resveratrol helped alleviate damage to the liver, kidney and pancreas in diabetic mice, possibly by reducing inflammation. It is coincident with the fact that our histopathological studies have shown a partial recovery in pancreatic cells. Similar results in liver and kidney tissues showed Alam et al. in 2015 when conducting a study in mice which were induced to diabetes and then treated with riboflavin in the presence and absence of light. Recovery in these organs was surprising even in those who were not exposed to light, so it is concluded that riboflavin has an essential role in the protection of oxidative stress caused by the conditions in the diabetic.

\section{CONCLUSIONS}

Chaya extracts (Cnidoscolus chayamansa) from the Maya and north-central regions of Mexico have equal potential as an aid in the control of diabetes and regenerative effect in pancreas.

\section{ACKNOWLEDGMENTS}

The authors acknowledge the funding of the Science and Technology Council (CONACYT-COCYTED).

\section{REFERENCES}

Alam M, Iqbal Sarah, Nasem I. Amelorative effect of rivoflavin on hyperglycemia, oxidative stress and DNA damage in type-2 diabetic mice: mechanistic and therapeutics strategies. Arch Biochem Biophys. 2015;584:10-19.

Balasubashini MS, Rukkumani, Viswanathan P, Venugopal PM. Ferulic acid alleviates lipid peroxidation in diabetic rats. Phytother Res. 2004;18(4):310-314.

Becquer L, Gómez T. Molina JL, Artiles D, Clapés S. Diabetogenic action of streptozotocin in an experimental model of neonatal induction. Biomedica. 2016:36(2):230-8.

Chavez AA, Ledezma ED, Álvarez S, Ferreira RG, Gómez OL, Galar MM. Evaluation of a type 2 diabetes model to study the hypoglycemic activity of glibenclamide. Rev Mex Cienc Farm. 2007;38(3):5-11.

ChavezOR, de la Vega R, de la VegaEB. Oral hypoglucemiants: pharmacological properties and therapeutic uses. Rev Posgrado Cátedra VIa. 2001;106:8-12.

Kuti JO, Torres ES. Potential nutritional and health benefit of tree spinach. J Janick ed. 1996 [on line] consulted on 23th august 2018. Available on: https://hort.purdue.edu/newcrop/ proceedings1996/V3-516.html.

Manikandan R, Beulaja M, Thiagarajan R, Asokan P, Subramanian P, Nayaranan M et al. Protective effect of ferulic acid and resveratrol against alloxan-induced diabetes in mice. Eur J Pharmacol. 2012;690(1-3):226-235.

Moya L, Alvarodíaz A, Hernández AE, Llera L, Salas E. Qualitative and quantitative composition of the chaya fresh leaves. Ciencia Tecnol Alimentos. 2013;23(1):60-62.

Orsolic N, Goran G, Vera G, Domagoj D, Zvjezdana SP, Damir S. DNA-protective effects of quercetin or naringenin in alloxan -induced diabetic mice. Eur J Pharmacol. 2011;656(13):110-118.

Pan Reac AppliChem. Hematoxiline-eosine stain. JMB, 2017; ver. 2: 1-4.

Shih JT, Chin SH, Mei CM, Wing YK, Hui YH, Mei CY. Anti-inflamatory and antificrotic effect of naringenin in diabetic mice. J Agric Food Chem. 2012;60(1):514-521.

Valenzuela SR, Morales RM, Verde SM, Oranday C, Preciado R, González JA, Esparza RJ. Cnidoscolus chayamansa organic hydroponic and its hypoglicemic capacity, nutraceutical quality and toxicity. Rev Mex Cien Agr. 2015;6(4):815-825.

Received for publication on 24th September 2018 Accepted for publication on $13^{\text {th }}$ November 2018 